\title{
Tubular Type of Basal Cell Adenoma of Parotid Gland: A Rare Entity
}

\author{
${ }^{1}$ Pratik Dipak Shah, ${ }^{2}$ Srijon Mukherji
}

\begin{abstract}
Basal cell adenoma (BCA) is a significantly rare benign salivary gland neoplasm that includes isomorphic basaloid cells. Presence of myoepithelial cell is a characteristic of this tumor. Basal cell adenoma accounts for only 1 to $2 \%$ of all salivary gland epithelial tumors. The goal of the paper is to report a rare case of tubular type of BCA arising from parotid gland and discuss its management.
\end{abstract}

Keywords: Basal cell adenoma, Myoepithelial cells, Parotid gland.

How to cite this article: Shah PD, Mukherji S. Tubular Type of Basal Cell Adenoma of Parotid Gland: A Rare Entity. J Contemp Dent 2015;5(3):184-187.

\section{Source of support: Nil}

\section{Conflict of interest: None}

\section{INTRODUCTION}

Salivary gland tumors are uncommon and constitute 2 to $6.5 \%$ of all head and neck tumors. ${ }^{1}$ Basal cell adenoma (BCA) is a significantly rare benign epithelial tumor of the salivary gland, accounting 1 to $2 \%$ of all salivary gland epithelial tumors. More than $80 \%$ of BCA arise in major salivary gland, mostly the parotid gland. It derives its name from the appearance of the tumor which shows isomorphic basaloid cells with a prominent basal cell layer. ${ }^{2-4}$ It usually appears as firm, mobile and slow growing mass. Basal cell adenoma, as defined by WHO, is a distinctive benign neoplasm composed of basaloid cells organized with a prominent basal cell layer and distinct basement membrane-like structure and no myxochondroid stromal component as seen in pleomorphic adenomas. ${ }^{5}$ These tumors affect patients between their 5 th and 7 th decades and 2:1 female predominance for most of the basal cell adenoma. ${ }^{5,6}$ Histologically four characteristic patterns have been described. Solid, trabecular, membranous,

\footnotetext{
${ }^{1}$ Surgical Fellow, ${ }^{2}$ Director and Chief Consultant

1,2Department of Oral and Maxillofacial Surgery, Calcutta Institute of Maxillofacial Surgery, Kolkata, West Bengal, India

Corresponding Author: Pratik Dipak Shah, Surgical Fellow Department of Oral and Maxillofacial Surgery, Calcutta Institute of Maxillofacial Surgery, Kolkata, West Bengal, India, Phone: 07926425871, e-mail: pratikdshah.2711@gmail.com
}

and presence of a basaloid cellular layer with a stockade pattern and rounded by hyaline substance. ${ }^{7}$ The goal of this paper is to add on to the literature one more case of $\mathrm{BCA}$ arising from major salivary gland, more commonly the parotid gland.

\section{CASE REPORT}

A 80-year-old male patient reported to Calcutta Institute of Maxillo Facial Surgery in the month of June 2012 with chief complain of solitary painless swelling below lobule of ear over left side since 8 years. Swelling was insidious in onset which started as a small mass initially and gradually progressed to present size. Clinical examination revealed a thin built patient with well defined extra oral swelling over the left side of the face below the lobule of ear, extending anteroposteriorly between posterior border of the ramus of the mandible and anterior border of the sternocleidomastoid muscle (Fig. 1). There was a raised ear lobule over left side which was a classical sign of parotid tumor. There was no functional deficit of cranial nerve VII which supplies muscles of facial expressions. Lesion was around $3 \times 5 \mathrm{~cm}$ in diameter, firm, freely moveable and nontender in nature. Skin over the swelling was smooth and pinchable and did not show any secondary changes. Plain and contrast enhanced CT scan of neck revealed large well defined thick walled peripherally enhancing homogenously hypodense lesion seen at left parotid region measuring $42 \times 30 \mathrm{~mm}$. The mass was displacing the internal jugular vein to left side (Fig. 2).

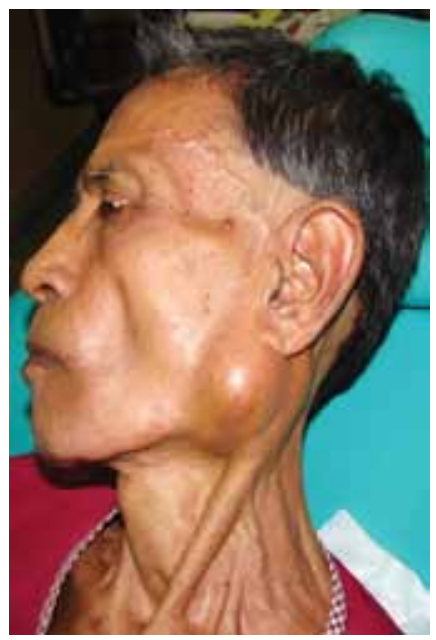

Fig. 1: Parotid swelling over left side of face 
Patient was undertaken for surgical resection of total parotid gland of left side. Skin incision was placed anterior to the ear, continued downward past the tragus, curved back under the ear and finally turned downwards to descend along the sternocleidomastoid muscle (Fig. 3) The anterior flap was created superficial to the parotid fascia to afford access to the appropriate dissection plane. Vertically-oriented blunt dissection was performed to minimize the risk of injury to the distal branches of the facial nerve. The face was observed for muscle twitch. The flap was raised until the anterior border of the parotid gland. The posterioinferior incision in the neck crease was deepened, exposing and then dividing the platysma. Careful dissection was performed to define the relationship of the parotid tail to the anterior border of the sternocleidomastoid muscle. The parotid tail was dissected away from the sternocleidomastoid. Vertical traction was applied to the gland surface to facilitate exposure (Fig. 4). Large deep lobe with tumor was excised first with facial nerve above (Figs 5 and 6). Next facial nerve was skeletonized and thus superficial parotid lobe was

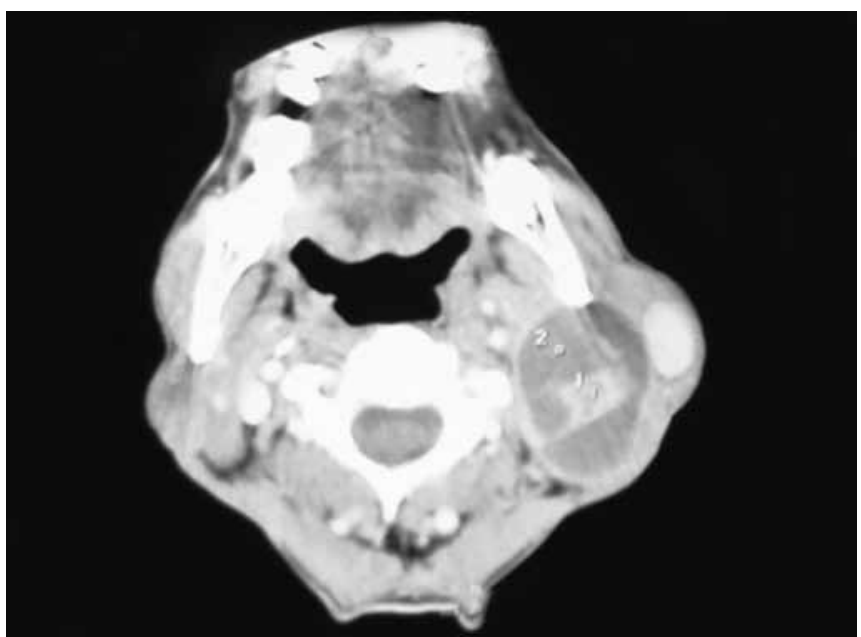

Fig. 2: Computed tomography showing large well defined hypodense swelling over left parotid region

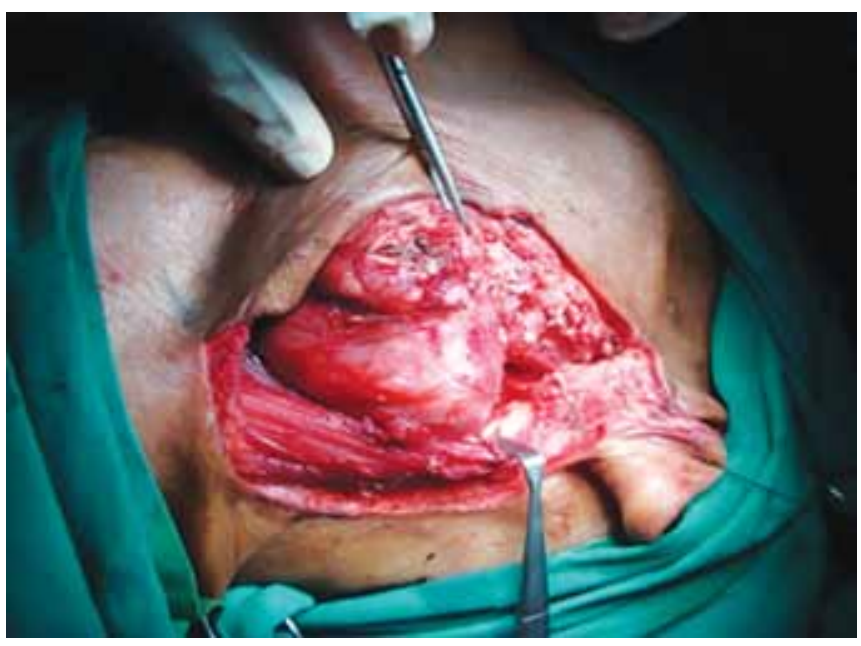

Fig. 4: Vertical traction applied to gland to facilitate exposure freed and excised (Figs 7 to 9). One small buccal branch was divided and later anastomosed with prolene 8-0. Hemostasis was achieved and drain was inserted. Parotid fascia was closed using vicryl 3-0 and skin closure was performed using ethilon 4-0.

Histopathology revealed capsulated lesion containing strands and tubules of small darkly stained epithelial cells with scanty cytoplasm. The tubules had an epithelial cells and a mantle layer of myoepithelial cells. The overall histopathological features of specimens were suggestive of tubular type of basal cell adenoma (Fig. 10).

\section{DISCUSSION}

Basal cell adenoma is a rare, benign epithelial neoplasm of salivary gland which was first described by Kleinsasser and Klein in 1967 and placed in the old WHO classification under monomorphic adenomas. ${ }^{8}$ In 1983 Gardner and Daley were the first authors who made the distinction between basal cell adenoma and canalicular adenoma. However, since 1991, according to the 'Salivary Glands Tumors Histological Classification' of the World Health

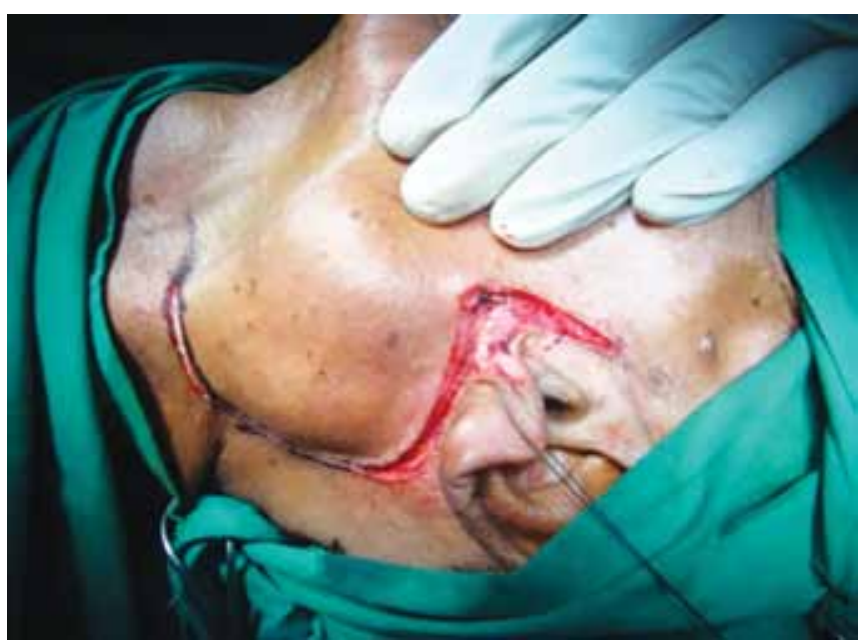

Fig. 3: Standard parotidectomy incision

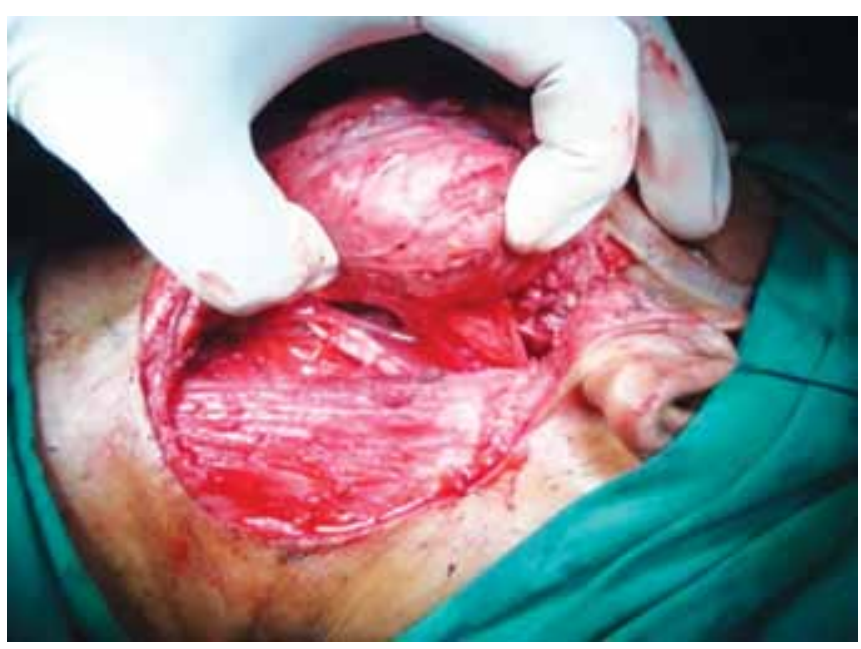

Fig. 5: Tumor involving deep lobe of parotid gland 
Organization, the name of this lesion was changed to basal cell adenoma, excluding the word 'monomorphic'. According to literature, malignant transformation occurs in $4.3 \%$ of BCA. ${ }^{10}$ Basal cell adenoma frequently occurs in people of over 50 years of age as a unilateral tumor

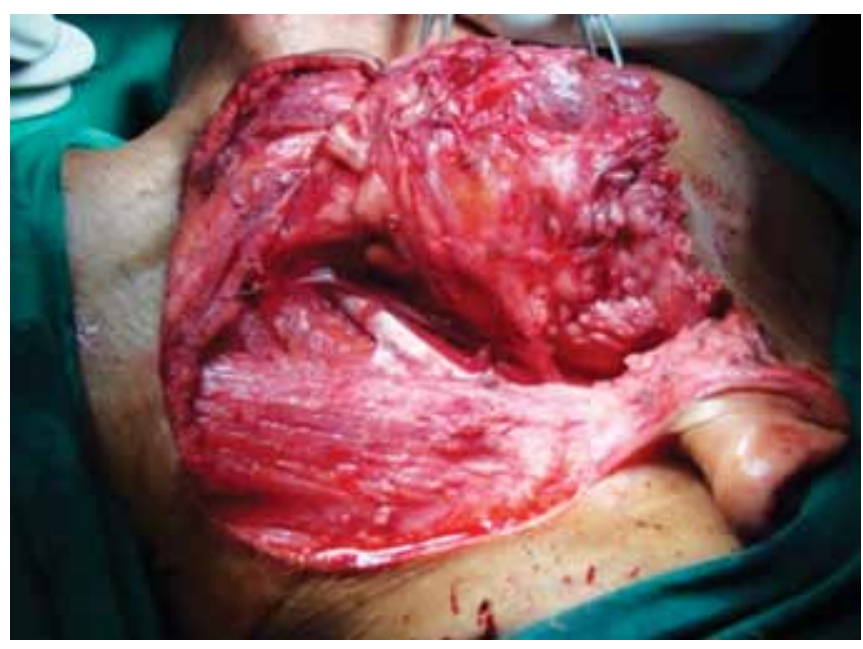

Fig. 6: Deep lobe tumor excised

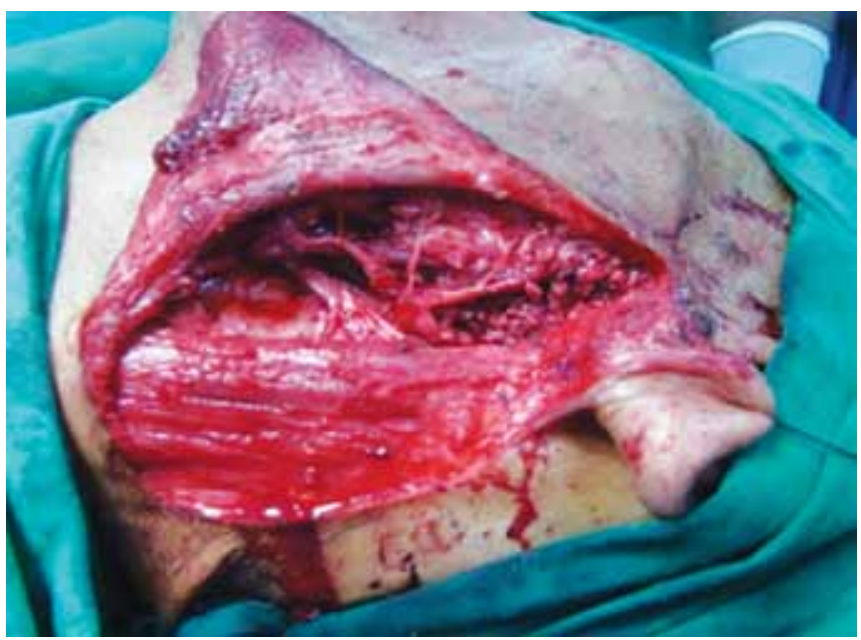

Fig. 8: Preservation of facial nerve after excising superficial and deep lobe of parotid gland

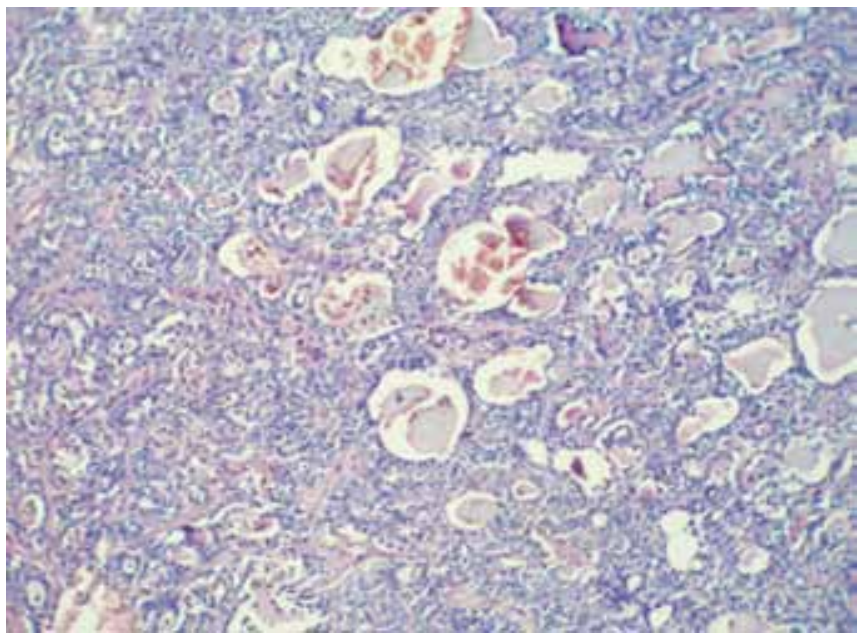

Fig. 10: Histopathology revealing tubules had epithelial cells and a mantle layer of myoepithelial cells with a well-circumscribed round or oval appearance. A painless, slowly enlarging mass is the most common clinical symptom. Basal cell adenoma tumors are usually smaller than $3 \mathrm{~cm}$. In the present patient, the site of occurrence, past history, age and sex were compatible

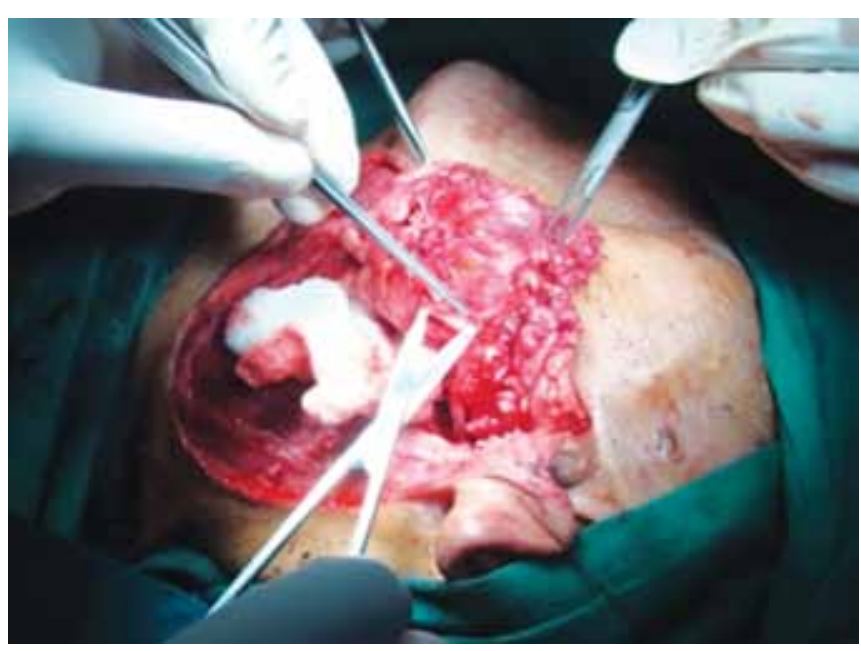

Fig. 7: Facial nerve skeletonization

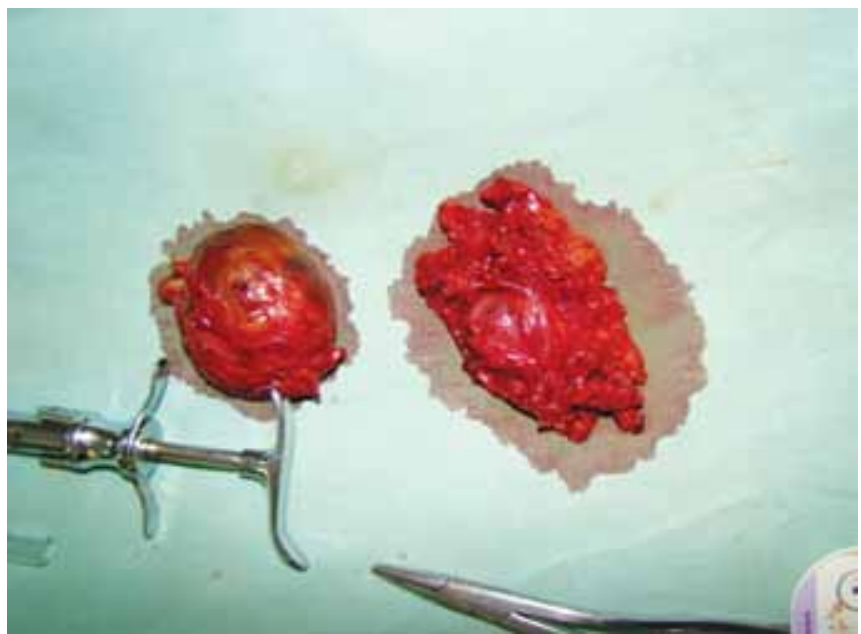

Fig. 9: Excised specimens of superficial and deep lobe tumor of parotid gland

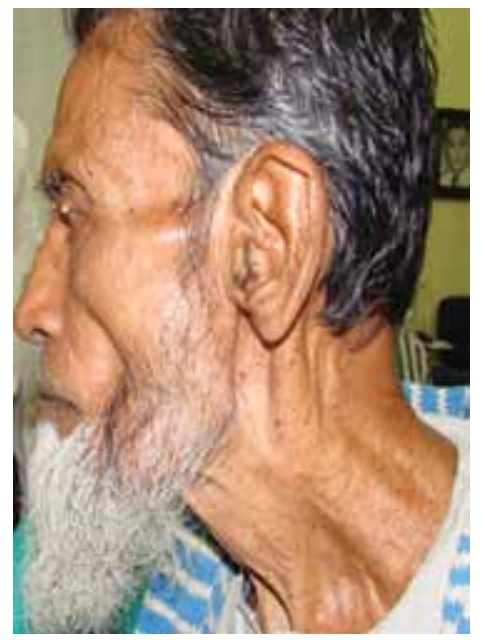

Fig. 11: One and half years postoperatively 
with those written in previous reports, but the tumor size was not compatible. Basal cell adenocarcinoma shares common clinical and histological similarities with BCA. Cytology differences, infiltration and perineural invasion help to distinguish basal cell adenocarcinoma from BCA. Usually myoepithelial cells remain absent in benign mixed tumors and other salivary gland tumors however its presence has been referred as characteristic of this tumor. In our case also microscopically we found tubules had a mantle layer of myoepithelial cells. Due to overlapping histomorphologic and common cellular composition of basal cell adenoma variants with, pleomorphic adenoma and myoepithelioma, its diagnostic recognition becomes notoriously difficult in surgical pathology. Immunohistochemistry with specific antibodies like $\alpha$-smooth muscle actin, calponin, smooth muscle myosin heavy chain defines myoepithelial cell participation in BCA and distinguishes from other salivary gland adenomas. Reported benign tumors of the parotid gland are pleomorphic adenoma, BCA and other unspecified monomorphic adenomas. These lesions are considered nonaggressive with recommended treatment being parotidectomy. Recurrence rate is very low and lesions can be completely resected. In the present case we performed total parotidectomy without mandibular split with preservation of facial nerve. Patient is being followed up at regular interval, patient regained functions of facial nerve postoperatively and there is no recurrence seen within one and half year period (Fig. 11).

\section{CONCLUSION}

Herein the goal of this paper is to add on to the literature one more case of this rare tumor from parotid gland. It is important to differentiate BCA from pleomorphic adenoma, adenoid cystic carcinoma and basal cell adenocarcinoma, to which it may bear resemblance. The surgeon must consider patient's clinical symptom, radiological and histological features to reach diagnosis. Treatment of BCA should aim at complete resection of tumor. There is no role of postoperative chemotherapy or radiation therapy if adequate excision is performed.

\section{REFERENCES}

1. Leegaard T, Lindeman H. Salivary-gland tumors. Clinical picture and treatment. Acta Otolaryngol Suppl 1969;263: 155-159.

2. Jeong AK, Lee HK, Kim SY, Cho KJ. Basal cell adenoma in the parapharyngeal space: MR findings. Clin Imaging 2001;25(6):392-395.

3. Luna MA, Mackay B. Basal cell adenoma of the parotid gland: case report with ultrastructural observations. Cancer 1976;37(3):1615-1621.

4. Som PM, Brandwein MS, Som PM, Curtin HD. Salivary glands: anatomy and pathology. Head and Neck Imaging. St Louis: Mosby 2003:2084-2085.

5. Jang M, et al. Basal cell adenoma in parotid gland: CT and MR findings. Am J Neuroradiol 2004 Apr;25(4):631-635.

6. Fantasia JE, Neville BW. Basal cell adenomas of minor salivary glands. A clinicopathologic study of seventeen new cases and review of literature. Oral Surg 1980;50(5):433-440.

7. Nagao G. Histopathologic studies of basal cell adenoma of the parotid gland. Cancer 1982;50(4):736-745.

8. Pogrel MA. The intraoral basal cell adenoma. J Craniomaxilla Facial Surg 1987;15(6):372-375.

9. Dib E, De Carvalho. Basal cell adenoma: a case report. J Oral and Maxillofac Surg 1997;55(11):1323-1325.

10. Nagao T, Sugano I, Ishida $Y$, Matsuzaki O, Konno A, Kondo Y, et al. Carcinoma in basal cell adenoma of the parotid gland. Pathol Res Pract 1997;193(3):171-178. 